\title{
Monetary Policy Analysis in Backward-Looking Models
}

\author{
Jesper Lindé*
}

January 28, 2000

\begin{abstract}
In this paper, I investigate quantitatively how sensitive a typical backwardlooking model used in monetary policy analysis are to the Lucas critique. To do this, I use a real business cycle model with money calibrated using a monetary policy rule for nominal money growth. This policy rule is then estimated using US data for different monetary regimes. The estimated standard backward-looking model display considerable parameter instability, both from a statistical and economic point of view, when the parameters in the estimated Taylor-type monetary policy rule change. The findings suggest that the robustness of the conclusions in the literature on the relative merits of alternative monetary policy rules should be checked in an equilibrium framework.
\end{abstract}

Keywords: Lucas critique; real business cycle model; Taylor rules; aggregate supply; aggregate demand.

JEL Classification Numbers: C52, C22, E41.

*Research Department, Sveriges Riksbank. Address: SE-103 37 Stockholm, Sweden. E-mail: jesper.linde@riksbank.se. I would like to thank Tor Jacobson, Søren Johansen, Marianne Nessén, Paul Söderlind, Ulf Söderström and Anders Vredin for helpful comments and suggestions. I have also benefitted from comments by participants in the conference "The Econometrics of Policy Evaluation" in Paris (10-12 January, 2000) and by seminar participants at Sveriges Riksbank and the Stockholm School of Economics. 


\section{Introduction}

In a very influential article, Lucas (1976) raised serious critique against econometric models that were used for policy evaluation. Lucas's argument was that shifts in economic policy change how policy affects the economy since agents in the economy are forward rather than backward-looking and adapt their expectations and behavior to the new policy stance. Thus, past behavior can be a poor guide for assessing the effects of policy actions. For this reason, Lucas concluded that reduced-form economic and econometric models cannot provide useful information about the actual consequences of alternative policies.

Instead, Lucas (1975, 1977), Kydland and Prescott (1982) and others initiated a new research program, often termed the real business cycle (or equilibrium business cycle) approach, where the models used for policy analysis are supposedly immune against the Lucas critique in that they are equilibrium models with forward-looking behavior. ${ }^{1}$ Other researchers have been concerned with the applicability of the Lucas critique in practice, see e.g. the discussion in Sims (1982). Engle, Hendry and Richard (1983) introduced the concept of super exogeneity, and argued that it could be used to test for the empirical relevance of the Lucas critique. Subsequent papers (e.g. Engle and Hendry, 1993) have shown how this concept can be applied.

Fuhrer (1997) maintains that backward-looking behavior seems to be a better approximation of reality than forward-looking behavior. Estrella and Fuhrer (1999) also argue that the Lucas critique is an empirically testable hypothesis. They provide evidence that when there is a change in monetary policy regime, some forward-looking models may be less stable than their better fitting backward-looking counterparts, which they argue is an observation inconsistent with the Lucas critique. In addition, most - if not all - of the many papers which have used the concept of super exogeneity to examine the Lucas critique empirically have found no evidence in favor of the proposition; see the survey by Ericsson and Irons (1995). But in a recent study, Lindé (1999) finds that the power of the super exogeneity test is very low in small samples. Thus, it is still an open issue whether

\footnotetext{
${ }^{1}$ Later work has questioned the view that $\mathrm{RBC}$-models with a representative agent are immune against the Lucas critique, see e.g. Geweke (1985) and Altissimo, Siviero and Terlizzese (2000).
} 
the Lucas critique is empirically important or not. ${ }^{2}$

Recently, the empirical relevance of the Lucas critique has received increased attention. A possible explanation for this is the extensive use of backward-looking models in monetary policy analysis; cf. Ball (1997), Svensson (1997), Rudebusch and Svensson (1998) and Taylor (1999). In this class of models, where the structure of the model economy is assumed to be unaffected by changes in economic policy, a considerable amount of effort has been devoted to examining the relative merits of alternative proposed monetary policy rules. Now, if the Lucas critique is valid and quantitatively important, this type of policy experiments may produce misleading results.

Because the empirical relevance of the Lucas critique is still is an open question and hard to test on data, I think it is useful, as a first step, to investigate how important the Lucas critique seems to be for these backward-looking models. More specifically, it is of interest to examine, first, if changes in the monetary policy rule lead to changes in the reduced form parameters that are economically meaningful, and second, if the observed changes in the reduced form parameters are significant in a statistical sense.

In this paper, I examine these two questions in greater detail. My approach is to set up a slightly modified version of Cooley and Hansen's (1995) real business cycle model with money. The modification is that the model here includes government expenditures and a Taylor-type policy rule (see Taylor, 1993) for nominal money growth similar to the rule analyzed by McCallum (1984, 1988). For model technical reasons it is not possible to use a nominal interest rate rule directly, but it is shown in the paper that the rule for nominal money growth can be rewritten as a standard Taylor-type rule in the nominal interest rate. The policy rule for nominal money growth is then estimated using U.S. data for the recent periods in office of Federal Reserve's chairmen Arthur Burns, Paul Volcker, and Alan Greenspan. According to Judd and Rudebusch (1998), the conduct of monetary policy has varied systematically between these periods. ${ }^{3}$ By calibrating the

\footnotetext{
${ }^{2}$ The findings of the paper by Lindé also have some general implications for the empirical testing of the relevance of backward versus forward looking models. First, only the true forward looking model will have parameters invariant to the monetary regime, and the preliminary results in Estrella and Fuhrer (1999), suggesting that the Lucas critique is not important in practice, may be due to model misspecification and/or that the tests have weak power in small samples.

3 Judd and Rudebusch (1998) start out by noting that there is instability in the Fed reaction function. They then find support for the hypothesis that the Fed monetary policy rule has varied systematically with the different periods in office of Fed chairmen Burns, Volcker, and Greenspan. As in their analysis,
} 
equilibrium model with different estimated monetary policy regimes, I study the properties of the reduced-form parameters in the Rudebusch and Svensson (1998) model by means of simple Monte Carlo simulations.

The results in the paper are as follows. Firstly, it is shown that the reduced form parameters of the Rudebusch and Svensson model change in a statistically significant way when the monetary policy rule changes. Secondly, the changes in the parameters are not only important according to a statistical criteria, they are also very important from an economic point of view. For instance, in the aggregate supply curve, the coefficient for output varies between -0.20 and 0.52 in the Rudebusch and Svensson model which of course has huge implications for policy analysis.

The structure of the paper is as follows. In the next section, I introduce the monetary equilibrium model, and indicate ways of computing the equilibrium. Estimation and calibration issues are addressed in Section 3. In Section 4, I present the Rudebusch and Svensson (1998) backward-looking model. Next, in Section 5, results of the Monte Carlo simulations regarding the sensitivity of the backward-looking models to the Lucas critique are reported. Section 6 concludes.

\section{The equilibrium model}

In this section, I describe and solve a slightly modified version of Cooley and Hansen's (1989, 1995) monetary equilibrium business cycle model. The model is a standard real business cycle model with some additional features. A stochastic nominal money supply interacts with a cash-in-advance technology and one-period nominal wage contracts, which creates short run real effects of nominal money supply shocks. As in Cooley and Hansen (1995), one period is one quarter. ${ }^{4}$

The difference between the model in this paper and the one in Cooley and Hansen (1995) is that the central bank is here assumed to use a policy rule when it decides on the nominal money supply growth in each period similar to that suggested by McCallum

\footnotetext{
the period with chairman Miller is omitted here because of his very short tenure.

4 I would like to emphasize that the qualitative aspects of the results in the paper are not at all dependent on whether I calibrate the model to match quarterly or yearly data.
} 
(1984, 1988). More specifically, the growth rate in nominal money supply in period $t$ is assumed to follow a Taylor-type policy rule and depend on the output gap, the difference between actual and targeted inflation rate (hereafter named inflation gap), an uncontrollable shock, and the growth rate in nominal money in period $t-1$. This specification is intended to capture the real world phenomenon that central banks use money supply to affect inflation and output gaps, although they act gradually and do not have perfect control of the process. It is shown that this monetary policy rule for nominal money growth can be rewritten as a Taylor rule for the nominal interest rate.

In the model I abstract from population and technological growth and represent all variables in per capita terms.

Finally, a notational comment; in the following, capital letters denote economy wide averages which the agent takes as given and small letters individual specific values which the agent internalizes.

\subsection{An equilibrium monetary business cycle model}

Infinitely many identical infinitely lived agents maximize expected utility with preferences summarized by

$$
\begin{gathered}
\mathrm{E}_{0} \sum_{t=0}^{\infty} \beta^{t} u\left(c_{1 t}, c_{2 t}, h_{t}\right), \\
u\left(c_{1 t}, c_{2 t}, h_{t}\right) \equiv \alpha \ln \left(c_{1 t}\right)+(1-\alpha) \ln \left(c_{2 t}\right)-\gamma h_{t}
\end{gathered}
$$

where $c_{1 t}$ is consumption of the "cash good" in period $t, c_{2 t}$ is consumption of the "credit good," and $h_{t}$ is the share of available time spent in employment which enters linearly in (1) because of the "indivisible labor" assumption (see Hansen, 1985). In (1), $\beta$ is the subjective discount factor, $\gamma$ the disutility the agent gets from working, while $\alpha$ reflects the trade-off between consumption of the cash and credit goods.

The flow budget constraint facing the agent is

$$
c_{1 t}+c_{2 t}+i_{t}+\frac{m_{t+1}}{P_{t}}+\frac{b_{t+1}}{P_{t}}=\left(\frac{W_{t}^{c}}{P_{t}}\right) h_{t}+R_{t}^{K} k_{t}+\frac{m_{t}}{P_{t}}+\left(1+R_{t-1}\right) \frac{b_{t}}{P_{t}}+\frac{T R_{t}}{P_{t}}
$$

where $i_{t}$ denotes the agent's investment, $m_{t+1}$ and $b_{t+1}$ the agent's holdings of nominal money and government bonds at the end of period $t, P_{t}$ the aggregate price level, $W_{t}^{c}$ 
the contracted nominal wage, $R_{t}^{K}$ the gross real return on the capital stock $k_{t}, R_{t-1}$ the nominal interest rate on government bonds between periods $t-1$ and $t$, and $T R_{t}$ nominal lump-sum transfers (or taxes if negative) from the government.

The agent has the following cash-in-advance constraint for the cash-good $c_{1 t}$,

$$
P_{t} c_{1 t}=m_{t}+\left(1+R_{t-1}\right) b_{t}+T R_{t}-b_{t+1}
$$

which always holds with equality since the nominal interest rate will always be positive in this model.

The government's budget constraint is

$$
P_{t} G_{t}+T R_{t}=M_{t+1}-M_{t}+B_{t+1}-\left(1+R_{t-1}\right) B_{t}
$$

where $G$ is exogenous public consumption expenditures, and $M$ and $B$ aggregate nominal money supply and government bonds. As in Cooley and Hansen (1995), I will assume that $B_{t}=0$ for $t \geq 0$ and only use it to compute the nominal interest rate in the economy. It can be shown that the nominal interest rate in equilibrium is given by

$$
R_{t}=\frac{\alpha}{1-\alpha} \frac{C_{2 t}}{C_{1 t}}-1
$$

where $C_{1 t}$ and $C_{2 t}$ are aggregate consumption of the cash and credit goods, respectively.

Government consumption, $G$, in (4) is assumed to be generated by the following stationary AR(1)-process,

$$
\ln G_{t+1}=\left(1-\rho^{\ln G}\right) \ln \bar{G}+\rho^{\ln G} \ln G_{t}+\varepsilon_{t+1}^{\ln G}, 0<\rho^{\ln G}<1, \varepsilon^{\ln G} \sim \text { i.i.d. } N\left(0, \sigma_{\ln G}^{2}\right) .
$$

Aggregate nominal money supply is assumed to evolve according to

$$
M_{t+1}=e^{\mu_{t}} M_{t}
$$

where the growth rate in nominal money supply in period $t$, defined as $\Delta \ln M_{t+1}$ and denoted $\mu_{t}$, is assumed to be determined by

$$
\begin{aligned}
\mu_{t} & =\eta \mu_{t-1}-\lambda_{\pi}\left(\pi_{t}-\pi^{*}\right)-\lambda_{Y}\left(\ln Y_{t}-\ln Y^{*}\right)+\xi_{t}, 0<\eta<1, \\
\xi & \sim \text { i.i.d. Log Normal, } \mathrm{E}[\xi]=(1-\eta) \bar{\mu}, \operatorname{Var}(\xi)=\sigma_{\xi}^{2}
\end{aligned}
$$


where $\pi_{t}$ is defined as $\ln P_{t}-\ln P_{t-1}$, and $\lambda_{\pi}$ and $\lambda_{Y}$ measure how the central bank reacts to deviations in the inflation $\left(\pi_{t}-\pi^{*}\right)$ and the output gap $\left(\ln Y_{t}-\ln Y^{*}\right)$, respectively. ${ }^{5}$ The implicit assumption underlying the specification in (8) is that the central bank tries to stabilize inflation and/or output, and one might think of (8) as an implementable monetary policy rule for a central bank which has been attached a conventional quadratic loss function in the inflation and output gaps. For simplicity, we will also set $\pi^{*}$ and $\ln Y^{*}$ in (8) equal to steady state nominal money supply growth $(\bar{\mu})$ and $\log$ of output $(\ln \bar{Y})$, respectively. The error term, $\xi$, as can be thought of as policy shocks from the perspective of the private sector. By introducing the persistence component $\eta \mu_{t-1}$, it is also assumed that the central bank reacts gradually to shocks which hits the economy.

The policy rule in (8) is not optimal. One important reason for choosing it nevertheless, is that is possible to derive a standard Taylor-type rule (see Taylor, 1998) for the nominal interest rate within the equilibrium model given the functional form of (8). Log-linearizing (5), (3) and (19), and substituting these equations into (8), it is possible to derive

$$
R_{t}=-\frac{\lambda_{\pi} \pi^{*}+\lambda_{Y} \ln Y^{*}}{(1-\overline{\hat{P}} \bar{G}) \kappa_{3}}+\frac{1+\lambda_{\pi}-\eta \mathrm{L}}{(1-\overline{\hat{P}} \bar{G}) \kappa_{3}} \pi_{t}+\frac{\lambda_{Y}+\overline{\hat{P}} \bar{G}(1-\eta \mathrm{L})(1-\mathrm{L}) \frac{\bar{Y}}{\bar{C}}}{(1-\overline{\hat{P}} \bar{G}) \kappa_{3}} \ln Y_{t}+(1+\eta-\eta \mathrm{L}) R_{t-1}+\varepsilon_{t}^{R}
$$

where $\varepsilon_{t}^{R} \equiv\left[\frac{-\xi_{t}+\left(\frac{\bar{C}-\bar{G}}{C}\right) \bar{P} \bar{G}(1-\eta \mathrm{L})(1-\mathrm{L}) \ln G_{t}-\delta \frac{\bar{K}}{\bar{C}} \bar{P} \bar{G}(1-\eta \mathrm{L})(1-\mathrm{L}) \ln I_{t}}{(1-\bar{P} \bar{G}) \kappa_{3}}\right], \kappa_{3}=\frac{\bar{C}-\bar{C}_{1}}{\bar{C}}>0$ (bar denotes steady state values) and $\mathrm{L}$ is the lag operator. Thus, it is possible to transform the Taylor inspired rule for nominal growth $\mu$ to a "standard" rule for the nominal interest rate $R$ in the model. But here it only possible to use the rule for $\mu$, because $R$ is an endogenous equilibrium price. ${ }^{6}$

The production function is assumed to have constant returns to scale and be of CobbDouglas type

$$
Y_{t}=e^{\ln Z_{t}} K_{t}^{\theta} H_{t}^{1-\theta}
$$

\footnotetext{
${ }^{5}$ Although we assume that $\xi$ is $\log$ normally distributed, we require that $\xi$ has mean $(1-\eta) \bar{\mu}$, and variance $\sigma_{\xi}^{2}$ as seen in (8). By using that $\mathrm{E}[\xi]=e^{\mathrm{E}[\ln \xi]+\frac{1}{2} \operatorname{Var}(\ln \xi)}$ and that $\operatorname{Var}(\xi)=\mathrm{E}\left\{(\xi-\mathrm{E}[\xi])^{2}\right\}=\mathrm{E}\left[\xi^{2}\right]-$ $[(1-\eta) \bar{\mu}]^{2}=e^{2 \mathrm{E}[\ln \xi]+\operatorname{Var}(\ln \xi)}-\left[(1-\eta) \bar{\mu}^{2}\right.$ since $\xi$ is log-normally distributed, one can pin down the mean and the variance for $\ln \xi$ as $-\frac{1}{2} \ln \left(\sigma_{\xi}^{2}+[(1-\eta) \bar{\mu}]^{2}\right)+2 \ln ((1-\eta) \bar{\mu})$ and $\ln \left(\sigma_{\xi}^{2}+[(1-\eta) \bar{\mu}]^{2}\right)-$ $2 \ln ((1-\eta) \bar{\mu})$ respectively.

${ }^{6}$ One potential problem with interpreting (9) as a standard Taylor-type rule is that the residual is presumably correlated with the arguments. In my view, however, this is not a specific issue for the model at hand, but rather a general problem that also has been acknowledged by many researchers, see e.g. McCallum and Nelson (1999).
} 
where $K_{t}$ and $H_{t}$ are aggregate (average) capital stock and hours worked, respectively, and $Z_{t}$ the technology level which is assumed to follow a stationary AR(1)-process (in natural $\operatorname{logs}$ )

$$
\ln Z_{t+1}=\rho^{\ln Z} \ln Z_{t}+\varepsilon_{t+1}^{\ln Z}, \varepsilon^{\ln Z} \sim \text { i.i.d. } N\left(0, \sigma_{\ln Z}^{2}\right) .
$$

Individual and aggregate investment in period $t$ produces productive capital in period $t+1$ according to

$$
k_{t+1}=(1-\delta) k_{t}+i_{t}
$$

and

$$
K_{t+1}=(1-\delta) K_{t}+I_{t}
$$

where $\delta$ is the rate of capital depreciation.

The perfect competition zero profit maximizing conditions for the representative firm are

$$
W_{t}^{c}=(1-\theta) e^{\ln Z_{t}}\left(\frac{K_{t}}{H_{t}}\right)^{\theta} P_{t}
$$

and

$$
R_{t}^{K}=\theta e^{\ln Z_{t}}\left(\frac{K_{t}}{H_{t}}\right)^{\theta-1} .
$$

The nominal wage $W_{t}^{c}$ is assumed to be set at the end of period $t-1$ (see Cooley and Hansen (1995) for further details on the nominal wage arrangement) as

$$
\ln W_{t}^{c}=\ln (1-\theta)+\mathrm{E}_{t-1} \ln Z_{t}+\theta\left(K_{t}-\mathrm{E}_{t-1} H_{t}\right)+\mathrm{E}_{t-1} P_{t}
$$

where $\mathrm{E}_{t-1}$ denotes the conditional expectations operator on all relevant information in period $t-1 .^{7}$ Moreover, households are assumed to transfer to the firms the right to choose aggregate hours worked in period $t, H_{t}$, to equate the marginal product of labor to the contracted wage rate. If we combine (14) and (16) in natural logarithms, using (11) below, we obtain

$$
\ln H_{t}=\mathrm{E}_{t-1} \ln H_{t}+\frac{1}{\theta}\left(\ln P_{t}-\mathrm{E}_{t-1} \ln P_{t}\right)+\frac{1}{\theta} \varepsilon_{t}^{\ln Z} .
$$

\footnotetext{
7 Note that $\ln K_{t}$ is known at the end of period $t-1$ through the equilibrium decision rules (see Appendix A).
} 
Similarly, one realizes that the natural logarithm of $h_{t}$ for an agent in equilibrium is given by

$$
\ln h_{t}=\mathrm{E}_{t-1} \ln H_{t}+\frac{1}{\theta}\left(\ln P_{t}-\mathrm{E}_{t-1} \ln P_{t}\right)+\frac{1}{\theta} \varepsilon_{t}^{\ln Z} .
$$

The aggregate resource constraint

$$
Y_{t}=C_{1 t}+C_{2 t}+I_{t}+G_{t} \equiv C_{t}+I_{t}+G_{t}
$$

also holds in every period where $C_{t}$ is total consumption.

\subsection{Equilibrium in the model}

The equilibrium in the model consists of a set of decision rules for the agents $\ln k_{t+1}=$ $k\left(\mathbf{S}_{t}, \ln k_{t}, \ln \hat{m}_{t}\right), \ln \hat{m}_{t+1}=\hat{m}\left(\mathbf{S}_{t}, \ln k_{t}, \ln \hat{m}_{t}\right)$ and $\ln h_{t}=h\left(\mathbf{S}_{t}, \ln k_{t}, \ln \hat{m}_{t}\right)$, and a set of aggregate decision rules $\ln K_{t+1}=K\left(\mathbf{S}_{t}\right), \ln H_{t}=H\left(\mathbf{S}_{t}\right), \ln \hat{P}_{t}=\hat{P}\left(\mathbf{S}_{t}\right)$ where $\mathbf{S}_{t}=\left[\ln Z_{t-1}, \varepsilon_{t}^{\ln Z}, \mu_{t-1}, \xi_{t}, \ln G_{t}, \ln K_{t}, \ln \hat{P}_{t-1}\right]^{\prime}$ such that; $(i)$ agents maximize utility, (ii) firms maximize profits, and (iii), individual decision rules are consistent with aggregate outcomes. Equilibrium condition (iii) implies that $k\left(\mathbf{S}_{t}, \ln K_{t}, 1\right)=K\left(\mathbf{S}_{t}\right)$, $\hat{m}\left(\mathbf{S}_{t}, \ln K_{t}, 1\right)=1$, and $h\left(\mathbf{S}_{t}, \ln K_{t}, 1\right)=H\left(\mathbf{S}_{t}\right)$ for all $\mathbf{S}_{t}$.

In Appendix A, I describe how to compute the equilibrium in this model.

\section{Estimation and calibration}

The parameters in the equilibrium model are determined in two ways. About half of the parameters $\left(\eta, \bar{\mu}, \sigma_{\xi}^{2}, \lambda_{\pi}, \lambda_{Y}, \rho^{\ln G}, \sigma_{\ln G}^{2}\right.$ and $\left.\bar{g} \equiv \frac{\bar{G}}{\bar{Y}}\right)$ are estimated on U.S. data 1960-1997 with Instrumental Variables method (IV) and Ordinary Least Squares (OLS). The other half of the parameters $\left(\alpha, \beta, \delta, \gamma, \theta, \rho^{\ln Z}\right.$ and $\left.\sigma_{\ln Z}^{2}\right)$ are adapted from Cooley and Hansen (1995), and chosen so that the model's steady state properties are consistent with U.S. growth facts.

To estimate the parameters $\eta, \bar{\mu}, \sigma_{\xi}^{2}, \lambda_{\pi}$, and $\lambda_{Y}$ in the monetary policy rule (8) for different Fed chairmen periods, I collected quarterly data on real gross national product per capita in natural logarithms $\left(\ln Y_{t}\right)$, growth rate in nominal money supply $\left(\mu_{t}\right)$ and the inflation rate in the consumer price index $\left(\pi_{t}\right)$. To compute measures of $\ln Y_{t}-\ln Y^{*}$ 
and $\pi_{t}-\pi^{*}$, I simply filtered the series for output and inflation rate with the HodrickPrescott (H-P) filter (see Hodrick and Prescott, 1997). ${ }^{8}$ It is standard to use H-P filtered output as measure of the output gap, but is less clear how to compute an appropriate measure of $\pi^{*}$ from historical data as discussed by Judd and Rudebusch (1998). ${ }^{9}$ Since the model does not distinguish between money controlled by the Fed (the monetary base, M0) and money used in private transactions (M2), I compromise between them and use M1 as a measure of money as in Cooley and Hansen $(1989,1995)$. The reason for estimating with IV rather than Ordinary Least Squares (OLS), is that OLS is likely to be a biased and inconsistent estimator due to the fact that we may have contemporaneous correlation between the error term and the regressors in (8). In terms of the theoretical model used in this paper, there will, via the equilibrium decision rules, be a positive correlation between the error term $\xi_{t}$ and the regressors $\pi_{t}$ and $\ln Y_{t}$ in (8). As instruments in the estimation, I therefore use $\left(\ln Y-\ln Y^{*}\right)_{t-1}, \mu_{t-1}$ and $\left(\pi-\pi^{*}\right)_{t-1}$ which are uncorrelated with the error term $\xi_{t}$ in (8). In addition to that, the estimated $\lambda_{\pi}$ and $\lambda_{Y}$ will be correlated in general, why inference must be conducted with great care.

I estimate the monetary policy rule (8) with IV for the whole sample period (1970Q11997Q4), for chairman Burns' office period (1970Q1 - 1978Q1), chairman Volckers' office period (1979Q3 - 1987Q2), chairman Greenspans' office period (1987Q3 - 1997Q4), and omit chairman Miller as in Judd and Rudebusch (1998) because of his short tenure. The results of the estimations are reported in Table 1 (a constant is included in the regressions but is omitted from the table).

All the regressions show signs of positive autocorrelation, so it is therefore difficult to say anything about the significance levels of these estimates. It should, however, be emphasized that the estimates are not sensitive to this autocorrelation. When I augmented the regressions with lags on the dependent variables until the autocorrelation was removed, the estimates of $\lambda_{\pi}$ and $\lambda_{Y}$ and $\eta$ changed very little. In addition, the $p$-value (i.e. the nominal significance level) for a joint $F$-test of the null hypothesis $H_{0}: \eta=\lambda_{\pi}=\lambda_{Y}=0$ is

\footnotetext{
${ }^{8}$ I use the common value 1600 (quarterly data) for the smoothness coefficient $\lambda$ in the H-P filter. See Appendix B for a detailed description of the raw data and data transformations.

${ }_{9}$ Although my approach regarding $\pi-\pi^{*}$ appears to be as good as any other considerable alternative (see Judd and Rudebusch), I have nevertheless experimented with other measures (such as the average inflation rate during a given chairmen's term), but it did not have any impact on the conclusions drawn in the paper.
} 
Table 1: IV estimation results for the monetary policy rule (8).

\begin{tabular}{|c|c|c|c|c|c|c|c|c|c|}
\hline \multirow{2}{*}{$\begin{array}{l}\text { Estimation } \\
\text { period }\end{array}$} & \multicolumn{9}{|c|}{ Estimation output } \\
\hline & $\hat{\eta}$ & $\hat{\lambda}_{\pi}$ & $\hat{\lambda}_{Y}$ & $\hat{\sigma}_{\xi}$ & $\overline{\bar{R}}^{2}$ & $\mathrm{D}-\mathrm{W}$ & $\mathrm{B}-\mathrm{G} \chi^{2}(4)$ & J-B & $T$ \\
\hline Whole & $\begin{array}{l}0.931 \\
(0.033)\end{array}$ & $\begin{array}{l}0.181 \\
(0.093)\end{array}$ & $\begin{array}{l}0.083 \\
(0.092)\end{array}$ & 0.0138 & 0.89 & 1.39 & $\begin{array}{l}33.33 \\
(0.000)\end{array}$ & $\begin{array}{l}0.400 \\
(0.819)\end{array}$ & 112 \\
\hline Burns & $\begin{array}{l}0.515 \\
(0.151)\end{array}$ & $\begin{array}{l}0.182 \\
(0.087)\end{array}$ & $\begin{array}{c}-0.166 \\
(0.148)\end{array}$ & 0.0073 & 0.73 & 1.96 & $\begin{array}{l}14.17 \\
(0.007)\end{array}$ & $\begin{array}{l}0.715 \\
(0.699)\end{array}$ & 33 \\
\hline Volcker & $\begin{array}{l}0.717 \\
(0.116)\end{array}$ & $\begin{array}{l}0.377 \\
(0.203)\end{array}$ & $\begin{array}{c}-0.137 \\
(0.249)\end{array}$ & 0.0158 & 0.73 & 1.59 & $\begin{array}{l}11.86 \\
(0.019)\end{array}$ & $\begin{array}{l}1.289 \\
(0.525)\end{array}$ & 32 \\
\hline Greenspan & $\begin{array}{l}0.919 \\
(0.054) \\
\end{array}$ & $\begin{array}{l}0.532 \\
(0.540)\end{array}$ & $\begin{array}{l}0.013 \\
(0.262)\end{array}$ & 0.0153 & 0.91 & 0.98 & $\begin{array}{l}17.37 \\
(0.002)\end{array}$ & $\begin{array}{l}1.249 \\
(0.536)\end{array}$ & 42 \\
\hline
\end{tabular}

Note: Standard errors in parenthesis for $\hat{\eta}, \hat{\lambda}_{\pi}$ and $\hat{\lambda}_{Y}$, and $p$-values in parenthesis for the Breusch-Godfrey autocorrelation test (null hypothesis no autocorrelation up to 4 lags) and the Jarque-Bera normality test (null hypothesis normally distributed residuals). A constant, $\left(\ln Y-\ln Y^{*}\right)_{t-1}, \mu_{t-1}$ and $\left(\pi-\pi^{*}\right)_{t-1}$ have been used as instruments. $T$ denotes the number of observations in the regressions.

around 0 for all regimes, as indicated by the model's satisfactory fit during the subsamples (measured by the multiple correlation coefficient $\bar{R}^{2}$ ). Not surprisingly, we get the highest estimates of $\lambda_{\pi}$ during chairmen Volcker and Greenspan periods of office, and the lowest for chairman Burns.

To examine if these parameter changes are in line with experiments conducted with interest rate rules, we insert the estimates of $\eta, \lambda_{\pi}$ and $\lambda_{Y}$ into the Taylor rule for the nominal interest rate in (9). It is then easy to verify that the resulting parameter changes in the Taylor rule for the nominal interest rate are well in line with typical parameter experiments considered in the interest rate rule literature.

To estimate $\rho^{\ln G}$ and $\sigma_{\ln G}^{2}$ in (6), I collected quarterly data series on real government expenditures on consumption and investment per capita in natural logarithms, and filtered the series with the Hodrick-Prescott (H-P) filter (see Hodrick and Prescott, 1997) to get a measure of $\ln G_{t}$. I then estimated (6) on the sample period $1960 Q 1$ to $1997 Q 4$ with OLS with the result (standard error in parenthesis)

$\ln G_{t}=\underset{(0.0485)}{0.8019} \ln G_{t-1}+\hat{\varepsilon}_{t}^{\ln G}, \hat{\sigma}_{\ln G}=0.009844, \mathrm{D}-\mathrm{W}=1.93, \bar{R}^{2}=0.64, \mathrm{~B}-\mathrm{G} \chi^{2}(4)=\underset{(0.0003)}{20.912}$.

Although the D-W statistic is satisfactory, the Breusch-Godfrey test for autocorrelation in (20) is significant and shows tendencies of positive autocorrelation. But when I augmented the estimation with more lags on the dependent variable to remove this autocorrelation, I found that the estimated parameters were largely unaffected.

To compute values for $\bar{\mu}$ and $\bar{g}$, I took averages of quarterly nominal money growth 
and the ratio of government expenditures to gross national product to get 0.01310 and 0.21038 respectively.

$\gamma$ is calibrated in the same way as in Cooley and Hansen (1995) and set so that hours worked as share of available time in steady state, $\bar{H}$, equals $0.30 .{ }^{10}$. The remaining parameters are directly taken from Cooley and Hansen; $\alpha$ is set to $0.84, \beta$ is set to 0.989 , $\delta$ is set to $0.019, \theta$ is set to 0.40 and $\rho^{\ln Z}$ and $\sigma_{\ln Z}$ are set to 0.95 and 0.00721 respectively.

\section{The Backward-looking model}

In this Section, I will briefly present the backward-looking model that I have chosen to study - the Rudebusch and Svensson (1998) model. The Rudebusch and Svensson model, which draws on the Svensson (1997) model, is intended to be a reasonable approximation of reality. It contains much richer dynamics than the simple Svensson model by allowing for four lags of inflation in the AS curve and two lags of output in the AD curve, since it is intended that the model should be empirically acceptable.

\subsection{The Rudebusch and Svensson (1998) model}

The Rudebusch and Svensson model is similar to many other models used for monetary policy analysis. It consists of aggregate supply (AS) and aggregate demand (AD) equations relating the output gap (the percentage deviation of output from its steady state level) and the inflation rate to each other and a monetary policy instrument, the (shortrun) interest rate. Formally, the model economy is described by the following equations

$$
\begin{aligned}
\pi_{t} & =\sum_{j=1}^{4} \alpha_{\pi, j} \pi_{t-j}++\alpha_{y} y_{t-1}+\varepsilon_{t}^{\pi}, \\
y_{t} & =\beta_{y, 1} y_{t-1}+\beta_{y, 2} y_{t-2}+\beta_{r} \sum_{j=1}^{4} \frac{1}{4}(i-\pi)_{t-j}+\varepsilon_{t}^{y} .
\end{aligned}
$$

In (21), the first equation is the AS curve (or Phillips curve), where the (annualized) inflation rate $\pi$ depends on past inflation rates, the output gap in the previous period

10 Formally, we have that $\gamma=\frac{(1-\theta)\left(\alpha \beta \frac{1}{e}+1-\alpha\right)\left(\frac{1-\beta(1-\delta)}{\beta \theta}\right)}{\bar{H}\left((1-\bar{g})\left(\frac{1-\beta(1-\delta)}{\beta \theta}\right)-\delta\right)}$, which can be used to compute $\gamma=3.404$ given the values for the other parameters. This value is higher than Cooley and Hansen's value (2.53) since I have government expenditures in the model. 
and a exogenous supply shock $\varepsilon^{\pi}$ (i.i.d. with zero mean and variance $\sigma_{\pi}^{2}$ ). The second equation in (21) is the $\mathrm{AD}$ curve, where the output gap $y_{t}$ is related to past output gaps $y_{t-1}$ and $y_{t-2}$, the average ex post real interest rate in the four previous periods, $\sum_{j=1}^{4} \frac{1}{4}(i-\pi)_{t-j}$, and an exogenous demand shock $\varepsilon_{t}^{y}$ (i.i.d. with zero mean and constant variance). The central bank, which is assumed to control the nominal interest rate $i_{t}$, thus affect the inflation rate with a two period lag. The monetary transmission mechanism is via output to the inflation rate. In the Rudebusch and Svensson framework, the sum of the estimated $\alpha_{\pi, j}$ 's is restricted to equal 1 to get an accelerationist Phillips curve where long-run monetary neutrality holds.

Rudebusch and Svensson estimate (21) on quarterly US data for the sample period $1961 Q 1$ to $1996 Q 2$. They cannot reject the hypothesis that $\sum_{j=1}^{4} \alpha_{\pi, j}$ equals 1 so they maintain that assumption throughout their analysis. But in the model framework here - when we have the equilibrium model as a datagenerating process - this restriction will not be fulfilled, so I therefore allow for a $\alpha_{\pi}$ different from 1 . Although Rudebusch and Svensson do not explicitly report any relevant statistics regarding the properties of $\varepsilon^{\pi}$ and $\varepsilon^{y}$, they test for structural stability in the equations and cannot reject the null hypothesis of no instability.

Rudebusch and Svensson measure the inflation rate $\pi_{t}$, the output gap $y_{t}$ and the ex post real interest rate $(i-\pi)_{t}$ in the following way. To get a measure of $\pi$, they compute $400\left(\ln p_{t}-\ln p_{t-1}\right)$ where $p$ is the quarterly chain-weighted GDP price index. $y_{t}$ is measured as the percentage gap between real output and potential output $100\left(\left(Y_{t}-Y_{t}^{*}\right) / Y_{t}^{*}\right)$. The ex post real interest rate (in period $t$ ) included in the $\mathrm{AD}$ curve is measured as $\frac{1}{4} \sum_{j=1}^{4}(i-\pi)_{t-j}$ where $i$ is the average quarterly federal funds rate and $\pi$ is the inflation rate defined previously. All variables are then demeaned prior to estimation of the model economy; hence no constants are included in the regressions.

Assuming a quadratic objective function for the central bank over inflation and output (for example, $L_{t} \equiv \pi_{t}^{2}+\lambda y_{t}^{2}+\nu \Delta i_{t}^{2}$ ), it is possible solve the central bank's problem subject to the estimated model economy summarized by (21). The resulting decision rule for the nominal interest rate as a (linear) function of current inflation rate, output gap and lagged nominal interest rate as in Taylor (1993), can then be used along with the estimated model 
economy to conduct policy analysis.

\section{$5 \quad$ Parameter stability in the backward-looking model}

In this section, I present the results of some simulation experiments designed to examine how robust the parameters in the backward-looking model are when there is a change in the monetary policy rule. I will discuss this issue from both a statistical as well as an economic point of view. I also present and motivate how the experiments have been carried out.

\subsection{Testing strategy}

To investigate whether the Lucas critique seems to be significant in a statistical sense for the backward-looking model, I have simulated the equilibrium model for the estimated monetary policy rules for nominal money growth and estimated the backward-looking model (21) on the simulated data.

The procedure in the simulations has been as follows:

1. Generate an articificial dataset by simulate the equilibrium model for $T$ periods under the assumption that the monetary policy rule changes completely unexpectedly after $T / 2$ periods from one regime to another (for example, from Burns to Volcker and Burns to Greenspan). ${ }^{11}$

2. Estimate (21) with OLS on the first $1, \ldots, T / 2$ observations in the simulated sample. Denote the estimated parameter vectors $\hat{\boldsymbol{\beta}}_{A S}$ (for aggregate supply) and $\hat{\boldsymbol{\beta}}_{A D}$ (aggregate demand) respectively.

3. Estimate $(21)$ with OLS on the last $T / 2+1, \ldots, T$ observations in the simulated sample. Denote the estimated parameter vectors $\hat{\boldsymbol{\alpha}}_{A S}$ and $\hat{\boldsymbol{\alpha}}_{A D}$ respectively.

\footnotetext{
11 The simulations are made in the GAUSS programming language, using the random number generator RDND with RDNDSEED set to $159425+i$ ter for $i t e r=1,2, \ldots, N$. To get a stochastic initial state in each simulation, the model is simulated for $T+100$ periods, where the first 100 periods are then discarded.
} 
4. Use a version of the $F$-test, often called the Chow breakpoint test, to examine if the null hypotheses

$$
\begin{aligned}
& H_{0}: \boldsymbol{\alpha}_{A S}=\boldsymbol{\beta}_{A S}, \\
& H_{0}: \boldsymbol{\alpha}_{A D}=\boldsymbol{\beta}_{A D},
\end{aligned}
$$

and

$$
H_{0}:\left(\boldsymbol{\alpha}_{A S}=\boldsymbol{\beta}_{A S}\right) \text { and }\left(\boldsymbol{\alpha}_{A D}=\boldsymbol{\beta}_{A D}\right)
$$

are rejected on appropriate significance levels. ${ }^{12}$

5. Repeat step 1 to step 4 many $(N)$ times to compute probabilities for how often the null hypotheses are maintained for the given significance level.

6. To get correct significance levels, steps 1 - 5 above are carried out twice. In the first round, small sample critical values are computed under the (true) null hypotheses $H_{0}: \boldsymbol{\alpha}_{A S}=\boldsymbol{\beta}_{A S}$ and $H_{0}: \boldsymbol{\alpha}_{A D}=\boldsymbol{\beta}_{A D}$ (that is, compute the distribution of $F$ statistics although there have been no regime shift). In the second round, these adjusted critical values are used in the $F$-test.

7. Now, if the computed probabilities in step 5 (in the second round) of rejecting parameter stability are higher/lower than the given significance levels, the Lucas critique is/is not relevant in this model in a statistical sense.

The critical assumptions in steps $1-6$ are clearly made in step $1-3$, and I would like to briefly comment on them. First, I have chosen to change monetary policy regime in the middle of the sample. The motivation behind this choice is that it gives the highest possible power in the testing. Secondly, I have chosen to model the once and for all change in monetary policy regime as a completely unexpected shift in the estimated monetary policy rule where I let the economy bring the state vector from the last period in the previous regime (period $T / 2$ ) to the first period in the new regime (period $T / 2+1$ ). Third, it is assumed that the monetary regime is perfectly credible and expected to last forever. By this procedure, I implicitly assume a first order Markov chain for the

\footnotetext{
12 See, for instance, Greene (1993) pp. 203-206 for how to compute the F-statistic.
} 
different monetary policy regimes where I let the diagonal elements in the transition matrix approach unity. The second and third assumptions are very convenient since they allows me to use the same decision rules for the first $T / 2$ periods and then change to new decision rules in the beginning of period $T / 2+1$ for the remaining $T / 2$ periods. Finally, I have chosen to use OLS as the estimation method - although it can be argued that it is an inconsistent estimator here - since it is a simple, fast and widely used method. I have made some experiments with a consistent estimator (the IV method), but the results were largely unaffected.

\subsection{Results for the Rudebusch and Svensson (1998) model}

The results of this exercise for the different estimated monetary policy rules for sample size $T=200$ (corresponding to 50 years of quarterly data), are provided in Table 2 . I have some experiments with other sample sizes $(T=100$ and $T=400)$, but the results were not much affected. In the estimations, all the variables involved in the regressions have been measured in precisely the same way as by Rudebusch and Svensson, whose measurement procedure was presented in Section 4.1. ${ }^{13}$

As seen in Table 2, the probabilities of rejecting the null hypothesis of parameter stability between regimes are clearly higher than the given significance levels in most cases. For the AS curve, we see that the probabilities of rejecting parameter stability are found to be low between the Burns and Volcker regimes and vice versa (0.007 and 0.006 respectively at the 1 percent level), implying that the Lucas critique is not quantitatively important in for the AS curve in these cases in a statistically significant way. This is quite natural since we can see in Table 1 that the estimated monetary policy rules for Burns and Volcker are most similar (low $\eta$, negative $\lambda_{Y}$ ) qualitatively. Turning to the AD curve, the probabilities for rejecting parameter stability are almost zero between the Greenspan and "whole sample" regimes. From Table 1, we see that these regimes are characterized by a high persistence component, and positive responses both to inflation and output gap.

\footnotetext{
13 To be able to generate reliable small sample critical values under the null (when there is no regime shift) in the first round, the model have been simulated $N=100000$ times. Note that the probabilities in the diagonal (when there is no regime shift) equals $0.05(0.01)$ at the $5(1)$ percent significance level since the same shocks have been used in the second round.
} 


\section{Table 2: $F$-test probabilities for rejecting the null hypothesis of parameter stability in the Rudebusch and Svensson (1998) model in $(21)$ at various significance levels.}

\begin{tabular}{|c|c|c|c|c|c|c|c|c|}
\hline \multirow[b]{4}{*}{ Benchmark regime } & \multicolumn{4}{|c|}{ Significance level 5 percent } & \multicolumn{4}{|c|}{ Significance level 1 percent } \\
\hline & \multicolumn{8}{|c|}{ Comparison regime } \\
\hline & WS & $\mathrm{B}$ & $\mathrm{V}$ & $\mathrm{G}$ & WS & $\mathrm{B}$ & $\mathrm{V}$ & $\mathrm{G}$ \\
\hline & \multicolumn{8}{|c|}{ The aggregate supply function; $H_{0}: \boldsymbol{\alpha}_{A S}=\boldsymbol{\beta}_{A S}$} \\
\hline Whole sample (WS) & 0.050 & 0.995 & 0.958 & 0.936 & 0.010 & 0.969 & 0.883 & 0.897 \\
\hline Burns (B) & 1.000 & 0.050 & 0.014 & 0.985 & 0.999 & 0.010 & 0.007 & 0.975 \\
\hline Volcker $(\mathrm{V})$ & 0.999 & 0.011 & 0.050 & 0.965 & 0.998 & 0.006 & 0.010 & 0.952 \\
\hline $\tan (\mathrm{G})$ & 0.985 & 0.928 & 0.759 & 0.050 & 0.969 & 0.863 & 0.691 & 0.010 \\
\hline Benchmark regime & \multicolumn{8}{|c|}{ The aggregate demand function; $H_{0}: \boldsymbol{\alpha}_{A D}=\boldsymbol{\beta}_{A D}$} \\
\hline Whole sample & 0.050 & 0.902 & 0.986 & 0.000 & 0.010 & 0.842 & 0.968 & 0.000 \\
\hline Burns & 0.953 & 0.050 & 0.178 & 0.919 & 0.919 & 0.010 & 0.130 & 0.838 \\
\hline Volcker & 0.990 & 0.116 & 0.050 & 0.954 & 0.986 & 0.073 & 0.010 & 0.822 \\
\hline Greenspan & 0.000 & 0.818 & 0.900 & 0.050 & 0.000 & 0.609 & 0.668 & 0.010 \\
\hline Benchmark regime & \multicolumn{8}{|c|}{ Either $A S$ - or AD-curve; $H_{0}:\left(\boldsymbol{\alpha}_{A S}=\boldsymbol{\beta}_{A S}\right)$ and $\left(\boldsymbol{\alpha}_{A D}=\boldsymbol{\beta}_{A D}\right)$} \\
\hline Whole sample & 0.050 & 0.999 & 0.993 & 0.936 & 0.010 & 0.992 & 0.981 & 0.897 \\
\hline Burns & 1.000 & 0.050 & 0.187 & 0.993 & 1.000 & 0.010 & 0.132 & 0.986 \\
\hline Volcker & 0.993 & 0.119 & 0.050 & 0.992 & 0.999 & 0.074 & 0.010 & 0.989 \\
\hline Greenspan & 0.985 & 0.970 & 0.987 & 0.050 & 0.969 & 0.916 & 0.955 & 0.010 \\
\hline \multicolumn{9}{|c|}{$\begin{array}{l}\text { Note: NC is shorthand notation for not computed. The } F \text {-test statistic underlying the computation of } \\
\text { the probabilities is defined as } \frac{\left(R_{U R}^{2}-R_{R}^{2}\right) / J}{\left(1-R_{U R}^{2}\right) /(T-k)} \text { and it follows the } F \text {-distribution with } J, T-k \text { degrees of } \\
\text { freedom where } J \text { is the number of parameter restrictions that are being tested (here, } J=k=2), T \text { is } \\
\text { the sample size, } R_{U R}^{2} \text { is the multiple correlation coefficient in the unrestricted regression (that is, from } \\
\text { the benchmark regime sample where } \hat{\boldsymbol{\beta}} \text { is computed) and } R_{R}^{2} \text { is the multiple correlation coefficient in } \\
\text { the restricted regression (that is, from the comparison regime sample using } \hat{\boldsymbol{\beta}} \text { instead of } \hat{\boldsymbol{\alpha}} \text { to compute } \\
\left.R_{R}^{2}\right) \text {. The small sample critical values are ?? for the Whole sample, Burns, Volcker and Greenspan } \\
\text { regimes at the } 5 \text { and } 1 \text { percent significance levels respectively, whereas the asymptotic critical values } \\
\text { are }\{2.65,2.26\} \text { and }\{3.88,3.11\} \text { at the } 5 \text { and } 1 \text { percent significance levels for } T=200 \text { and } J=\{3,5\} \text {. } \\
\text { The small sample critical values are generated under the null hypothesis in a first round of } N=100000 \\
\text { simulations, while the probabilities reported in the table are computed from a second round of simulations } \\
\text { (again, } N=100000) \text { where the small sample critical values are used in the testing. }\end{array}$} \\
\hline
\end{tabular}


One conclusion is therefore, as expected, that all three parameters in the monetary policy rule are important for the behavior of the parameters in the backward-looking models. In particular, $\eta$ and $\lambda_{Y}$ seem most important for the AS curve while $\eta$ seems to be most important for the $\mathrm{AD}$ curve.

However, the most interesting hypothesis to test - because both the AS and AD curve are used in policy analysis - is the null hypothesis of instability in either the AS or the AD curve. In Table2, the results for this hypothesis clearly indicate that the parameters in the Svensson model as a whole are not exogenous to the central banks optimization problem (and thus the parameters in the monetary policy rule).

From an economic point of view, it is also of particular interest to examine whether this instability is economically meaningful. To shed light on this issue, I present in Table 3 the OLS estimation results of the model (21) on simulated data generated by the equilibrium model for the estimated monetary policy rules in Table $1 .{ }^{14}$

We see from Table 3 that the results in Table 2 are confirmed. From an economic point of view, the estimated parameters in the model, in particular for the AS curve, are heavily affected by changes in the monetary policy rule. The output parameter in the AS equation varies from about -0.20 to 0.52 and the real interest rate coefficient in the $\mathrm{AD}$ equation, although low in general, also alters in sign. From an econometric point of view, the estimated equations often pass (in about $80-90$ percent on average) statistical tests for autocorrelation, as indicated by the Breusch-Godfrey statistics for autocorrelation. The adjusted r-squares are also satisfactory in most cases, the exception being the low adjusted r-square for the AS curve for the Greenspan regime. The reason for this is the estimated high value for $\lambda_{\pi}$ during the Greenspan regime, which drives down the autocorrelation (and the volatility) of the inflation rate. Consequently, all in all, an econometrician who estimates this model from the data would not immediately reject it for statistical reasons in most cases.

\section{[Importance of the Lucas critique in the model considered as a system with}

\footnotetext{
14 I have not been able to solve analytically for the reduced-form parameters as functions of the monetary policy rule parameters $\eta, \lambda_{\pi}$ and $\lambda_{Y}$ (and the other parameters in the equilibrium model). Therefore, I have been forced to estimate them on simulated data. I expanded the number of simulations until the (estimated) parameters coefficients converged in mean down to five digits, which required slightly less than 100000 simulations for $T=200$.
} 
Table 3: OLS estimation of the Rudebusch and Svensson model (21) for different regimes on simulated data.

\begin{tabular}{|c|c|c|c|c|c|c|c|c|c|}
\hline \multirow{2}{*}{$\begin{array}{l}\text { Estimation } \\
\text { period }\end{array}$} & \multicolumn{9}{|c|}{ Estimation output for the AS curve } \\
\hline & $\alpha_{\pi, 1}$ & $\alpha_{\pi, 2}$ & $\alpha_{\pi, 3}$ & $\alpha_{\pi, 4}$ & $\alpha_{y}$ & $R^{2}$ & $\mathrm{D}-\mathrm{W}$ & $\mathrm{B}-\mathrm{G} \chi^{2}(1)$ & B-G $\chi^{2}(4)$ \\
\hline Whole sample & 0.292 & 0.172 & 0.130 & 0.095 & -0.2029 & 0.62 & 2.03 & $\begin{array}{c}0.09 \\
(0.860)\end{array}$ & $\begin{array}{l}3.61 \\
(0.886)\end{array}$ \\
\hline Burns & 0.043 & 0.123 & 0.608 & 0.041 & 0.5207 & 0.34 & 2.04 & $\begin{array}{c}0.77 \\
(0.880)\end{array}$ & $\begin{array}{l}1.69 \\
(0.911)\end{array}$ \\
\hline Volcker & 0.110 & 0.134 & 0.053 & 0.024 & 0.4324 & 0.33 & 2.02 & $\begin{array}{c}0.92 \\
(0.937)\end{array}$ & $\begin{array}{l}1.30 \\
(0.953)\end{array}$ \\
\hline Greenspan & 0.086 & 0.034 & 0.195 & 0.009 & -0.0103 & 0.07 & 2.00 & $\begin{array}{l}1.03 \\
(0.918)\end{array}$ & $\begin{array}{l}4.47 \\
(0.909)\end{array}$ \\
\hline \multirow{2}{*}{$\begin{array}{l}\text { Estimation } \\
\text { period }\end{array}$} & \multicolumn{9}{|c|}{ Estimation output for the AD curve } \\
\hline & \multicolumn{2}{|c|}{$\beta_{y, 1}$} & \multicolumn{2}{|c|}{$\beta_{y, 2}$} & $\beta_{r}$ & $\bar{R}^{2}$ & $\mathrm{D}-\mathrm{W}$ & $\mathrm{B}-\mathrm{G} \chi^{2}(1)$ & B-G $\chi^{2}(4)$ \\
\hline Whole sample & \multicolumn{2}{|c|}{0.7901} & \multicolumn{2}{|c|}{0.1267} & -0.0154 & 0.80 & 2.01 & $\begin{array}{c}0.46 \\
(0.931)\end{array}$ & $\begin{array}{l}4.85 \\
(0.869)\end{array}$ \\
\hline Burns & \multicolumn{2}{|c|}{0.4741} & \multicolumn{2}{|c|}{0.3314} & 0.0140 & 0.51 & 2.12 & $\begin{array}{l}5.14 \\
(0.452)\end{array}$ & $\begin{array}{l}10.35 \\
(0.487)\end{array}$ \\
\hline Volcker & \multicolumn{2}{|c|}{0.4680} & \multicolumn{2}{|c|}{0.3218} & -0.0396 & 0.49 & 2.11 & $\begin{array}{l}4.38 \\
(0.520)\end{array}$ & $\begin{array}{l}10.36 \\
(0.507)\end{array}$ \\
\hline Greenspan & \multicolumn{2}{|c|}{0.6895} & \multicolumn{2}{|c|}{0.2135} & -0.0145 & 0.75 & 2.03 & $\begin{array}{l}0.81 \\
(0.895)\end{array}$ & $\begin{array}{c}4.81 \\
(0.872)\end{array}$ \\
\hline
\end{tabular}

Note: The values within parentheses measure the likelihood that the computed test statistics are insignificant (significance level 5 percent) for the Breusch-Godfrey's $\chi^{2}$-test (null hypotheses no 1st and/or 4th order autocorrelation). All the statistics reported are averages of $N=100000$ simulations of sample size $T=200$.

\section{(9). Remains to be written.]}

To sum up, the simulation results for the null hypothesis of instability in either the $\mathrm{AS}$ or the AD curve clearly indicate that the parameters in the Rudebusch and Svensson model as a whole are not exogenous to the central banks optimization problem (and thus the parameters in the monetary policy rule) using an equilibrium model with forwardlooking agents as a datagenerating process. Thus, the Lucas critique applies strongly to this model according to the equilibrium model.

\section{Concluding remarks}

\section{[Preliminary.]}

- Lucas critique potentially important quantitatively for backward-looking models.

- The robustness of the findings in this paper should be checked in other equilibrium models. 
- Results from the literature regarding the relative merits of alternative monetary policy rules in backward-looking models potentially misleading, at least at longer horizons.

- There is a potential need to check the robustness of the conclusions from this literature in a dynamic general equilibrium framework.

- One may argue that the results are due to wrongly specified monetary policy regimes/rule. I have done some experiments with a quadratic loss function of the form $L_{t}=\frac{1}{2}\left[\left(\pi_{t}-\pi^{*}\right)^{2}+\lambda\left(\ln Y_{t}-\ln Y^{*}\right)^{2}+\nu\left(\Delta i_{t}\right)^{2}\right](\Rightarrow$ choose coefficients $\eta$, $\lambda_{\pi}$ and $\lambda_{Y}$ in the monetary policy rule (8) that are consistent with minimization of this loss function) for the central bank for values of $\lambda$ equal to $0,0.2,1$ and 5 given $\nu=1$ as in Rudebusch and Svensson (1998) to find that the qualitative conclusions are unaffected.

- Not possible to use an interest rate rule directly in this framework. But I think that the results in this paper are robust against this critique since the parameter changes in the monetary policy rule for nominal money growth are not large in comparison with typical parameter changes in interest rate rules. To see this, insert the estimates of the monetary policy rule (8) in Table 1 in the Taylor-type rule for the nominal interest rate $(9)$.

- Another limitation of the paper is that I have implicitly assumed that the institutional design of the economy (that is, the one period nominal wage contacting assumption in the model) is unaffected by the monetary policy regime shifts. This assumption can be motivated by the real world observation that institutions, for example labor market arrangements, change very slowly over time. Consequently, the effects of institutional changes when testing for the Lucas critique in practice should be of "second order", while the effects of monetary policy regime shift examined in this paper should be of "first order". 


\section{Appendix A Computation of equilibrium}

In order to make all variables in the deterministic version of the model above converge to a steady state, I transform the nominal variables by dividing $m_{t+1}$ and $P_{t}$ with $M_{t+1}$, and $m_{t}$ with $M_{t}$. If we introduce the notation

$$
\hat{m}_{t+s} \equiv \frac{m_{t+s}}{M_{t+s}} \text { and } \hat{P}_{t+s} \equiv \frac{P_{t+s}}{M_{t+s+1}}
$$

and use the transformations to rewrite the equations (2), (3), (4), (8), (17) and (18), the representative agent's optimization problem can, following Hansen and Prescott (1995), be expressed as the recursive dynamic programming problem:

$$
\begin{aligned}
& V\left(\mathbf{S}_{t}, \hat{m}_{t}, k_{t}\right) \equiv \max _{\left\{\hat{m}_{t+1}, h_{t}, k_{t+1}\right\}}\left[\alpha \ln \left(c_{1 t}\right)+(1-\alpha) \ln \left(c_{2 t}\right)-\gamma h_{t}+\beta \mathrm{E}_{t} V\left(\mathbf{S}_{t+1}, \hat{m}_{t+1}, k_{t+1}\right)\right] \\
& \text { s.t. (10), (6), (11), } \\
& c_{1 t}=\frac{\hat{m}_{t}+e^{\mu_{t}}-1}{e^{\mu_{t}} \hat{P}_{t}}-G_{t}, \\
& c_{2 t}=(1-\theta) e^{\ln Z_{t}}\left(\frac{K_{t}}{H_{t}}\right)^{\theta} h_{t}+\left(1+R_{t}^{K}-\delta\right) k_{t}-k_{t+1}-\frac{\hat{m}_{t+1}}{\hat{P}_{t}}, \\
& \mu_{t}=\frac{\eta}{1+\lambda_{\pi}} \mu_{t-1}-\frac{\lambda_{\pi}}{1+\lambda_{\pi}}\left(\ln \hat{P}_{t}-\ln \hat{P}_{t-1}-\pi^{*}\right)-\frac{\lambda_{Y}}{1+\lambda_{\pi}}\left(\ln Y_{t}-\ln Y^{*}\right)+\frac{1}{1+\lambda_{\pi}} \xi_{t}, \\
& H_{t}-\mathrm{E}_{t-1} \ln H_{t}=\frac{1}{\theta\left(1+\lambda_{\pi}\right)+(1-\theta) \lambda_{Y}}\left(\ln \hat{P}_{t}-\mathrm{E}_{t-1} \ln \hat{P}_{t}\right)+\frac{1+\lambda_{\pi}-\lambda_{Y}}{\theta\left(1+\lambda_{\pi}\right)+(1-\theta) \lambda_{Y}} \varepsilon_{t}^{\ln Z}+\frac{\xi_{t}-(1-\eta) \bar{\mu}}{\theta\left(1+\lambda_{\pi}\right)+(1-\theta) \lambda_{Y}}, \\
& h_{t}-\mathrm{E}_{t-1} \ln H_{t}=\frac{1}{\theta\left(1+\lambda_{\pi}\right)+(1-\theta) \lambda_{Y}}\left(\ln \hat{P}_{t}-\mathrm{E}_{t-1} \ln \hat{P}_{t}\right)+\frac{1+\lambda_{\pi}-\lambda_{Y}}{\theta\left(1+\lambda_{\pi}\right)+(1-\theta) \lambda_{Y}} \varepsilon_{t}^{\ln Z}+\frac{\xi_{t}-(1-\eta) \bar{\mu}}{\theta\left(1+\lambda_{\pi}\right)+(1-\theta) \lambda_{Y}}, \\
& \ln K_{t+1}=K\left(\mathbf{S}_{t}\right), \ln H_{t}=H\left(\mathbf{S}_{t}\right), \ln \hat{P}_{t}=\hat{P}\left(\mathbf{S}_{t}\right) .
\end{aligned}
$$

In (A.1), $\mathbf{S}_{t}$ is a $1 \times 8$ row vector which contains all the aggregate state variables $\ln Z_{t-1}$, $\varepsilon_{t}^{\ln Z}, \ln G_{t}, \mu_{t-1}, \xi_{t}, \ln K_{t}, \ln \hat{P}_{t-1}$ and a constant term. If $\lambda_{\pi}=0$, then $\ln \hat{P}_{t-1}$ vanishes in $\mathbf{S}_{t}{ }^{15}$ In maximization of (A.1), the agent takes the economy-wide aggregate (average) variables as given. The functions $K, \hat{P}$ and $H$ describe the relationship perceived by agents between the aggregate decision variables and the state of the economy. As the solution to the problem in (A.1), we have the agent's decision rules $\ln k_{t+1}=k\left(\mathbf{S}_{t}, \ln k_{t}, \ln \hat{m}_{t}\right)$,

\footnotetext{
${ }^{15}$ Note that the household budget constraint on line 4 in (A.1) incorporates the fact that the contracted nominal wage divided by the price level equals the equilibrium marginal product of labor since firms unilaterally determine hours worked in period $t$.
} 
$\ln \hat{m}_{t+1}=\hat{m}\left(\mathbf{S}_{t}, \ln k_{t}, \ln \hat{m}_{t}\right)$ and $\ln h_{t}=h\left(\mathbf{S}_{t}, \ln k_{t}, \ln \hat{m}_{t}\right)$. The competitive equilibrium is obtained when the individual and average decision rules coincide for $\ln k_{t}=\ln K_{t}$ and $\ln \hat{m}_{t+1}=\ln \hat{m}_{t}=0$.

Since it is impossible to derive the decision rules analytically, I have used the same method as Cooley and Hansen (1995) and computed the decision rules numerically by approximating the original problem with a second order Taylor expansion around the constant steady state values in the nominal-growth adjusted economy. As a consequence of this approximation, the method produces linear decision rules (in natural logarithms for $K_{t+1}, H_{t}$ and $\left.\hat{P}_{t}\right)$. The algorithm utilized is described in detail in Hansen and Prescott (1995).

\section{Appendix B Data sources and definitions}

In this appendix, I provide the sources of the data collected in Table B.1 below.

Table B.1: The data set.

\begin{tabular}{|c|c|c|}
\hline Variables & Sample period & Source \\
\hline GNP & $1960 Q 1-1997 Q 4$ & FRED database, Federal Reserve Bank of St. Louis \\
\hline GEC & $7 Q 4$ & St. Louis \\
\hline M1 & $7 Q 4$ & ase, Federal $\mathrm{R} \epsilon$ \\
\hline POP & 1960-1996 & OECD Main Economic Indicators \\
\hline CPI & $1959 Q 1-1997 Q 4$ & FRED database, Federal Reserve Bank of St. Louis \\
\hline \multicolumn{3}{|c|}{$\begin{array}{l}\text { Note: All real macroeconomic variables are measured in } 1992 \text { billion U.S. dollars. Abbreviations; GNP } \\
\text { denotes real (fixed, seasonally adjusted) gross national product; GEC real (chained, seasonally adjusted) } \\
\text { government consumption and investment; M1 (not seasonally adjusted) nominal money supply 1; CPI } \\
\text { (not seasonally adjusted) consumer price index; POP average U.S. population (for 1997, POP is set equal } \\
\text { to average gross growth rate times the value for 1996). }\end{array}$} \\
\hline
\end{tabular}

The transformations made to generate the variables used in Table 1 are displayed in Table B.2.

Table B.2: Generation of composite quarterly data series.

\begin{tabular}{lcc}
\hline \hline Variable & Sample period & Calculation formula \\
\hline $\ln Y$ & $1960 Q 1-1997 Q 1$ & $\ln (\mathrm{GNP} / \mathrm{POP})$ \\
$\mu$ & $1960 Q 1-1997 Q 4$ & $\ln \left(\mathrm{M}_{t} / \mathrm{M}_{t-4}\right)$ \\
$\pi$ & $1960 Q 1-1997 Q 4$ & $\ln \left(\mathrm{CPI}_{t} / \mathrm{CPI}_{t-4}\right)$ \\
$\ln G$ & $1960 Q 1-1997 Q 4$ & $\ln (\mathrm{GEC} / \mathrm{POP})$ \\
\hline
\end{tabular}

Note: To get measures of $\ln Y-\ln Y^{*}, \ln G$ and $\pi-\pi^{*}, \ln Y, \ln G$ and $\pi$ are then subject to HodrickPrescott filtering with the smoothness coefficient $\lambda$ set to 1600 . 
To compute measures of the ratio of government expenditures to output and the growth rate in nominal money supply in steady state, $\bar{g}$ and $\bar{\mu}$ respectively, I computed the sums $\frac{1}{152} \sum_{t=1960 Q 1}^{1997 Q 4}\left(\mathrm{GEC}_{t} / \mathrm{GNP}_{t}\right)$ and $\frac{1}{152} \sum_{t=1960 Q 1}^{1997 Q 4}\left(1+\mu_{t}\right)^{\frac{1}{4}}-1$. 


\section{References}

Altissimo, Filippo, Siviero, Stefano and Terlizzese, Daniele, (2000), "How Deep Are The Deep Parameters?", manuscript, Research Department, Bank of Italy.

Ball, Laurence, (1997), "Efficient Rules for Monetary Policy", NBER Working Paper No. 5952, National Bureau of Economic Research.

Cooley, Thomas F. and Hansen, Gary D., (1989), "The Inflation Tax in a Real Business Cycle model", American Economic Review, Vol. 79, No. 4, pp. 733-748.

Cooley, Thomas F. and Hansen, Gary D., (1995), "Money and the Business Cycle", Chapter 7 in Cooley, Thomas F. (Ed.), Frontiers of Business Cycle Research, Princeton University Press, Princeton.

Engle, Robert F., Hendry, David F. and Richard, Jean-Francois, (1983), "Exogeneity", Econometrica, Vol. 51, No. 2, pp. 277-304.

Engle, Robert F. and Hendry, David F., (1993), "Testing Super Exogeneity and Invariance in Regression Models", Journal of Econometrics, Vol. 56, No. 2, pp. 119-139.

Ericsson, Neil R. and Irons, John S., (1995), "The Lucas Critique in Practice: Theory without Measurement", Chapter 8 in Hoover, Kevin D. (Ed.), Macroeconometrics: Developments, Tensions, and Prospects, Kluwer Academic Publishers, Boston.

Geweke, John, (1985) "Macroeconomic Modelling and the Theory of the Representative Agent", American Economic Review, Vol. 75, No. 2, pp. 206-210.

Greene, William H., (1993), Econometric Analysis, 2nd ed., Prentice-Hall Inc., New Jersey.

Hansen, Gary D., (1985), "Indivisible Labor and the Business Cycle", Journal of Monetary Economics, Vol. 16, No. 2, pp. 309-327.

Hansen, Gary D. and Prescott, Edward C., (1995), "Recursive Methods for Computing Equilibria of Business Cycle Models", Chapter 2 in Cooley, Thomas F. (Ed.), Frontiers of Business Cycle Research, Princeton University Press, Princeton.

Hodrick, Robert J. and Prescott, Edward C., (1997), "Postwar U.S. Business Cycles: An Empirical Investigation", Journal of Money, Credit and Banking, Vol. 29, No. 1, pp. $1-16$.

Judd, John P. and Rudebusch, Glenn D., (1998), "Taylor's rule and the Fed: 1970-1997", Federal Reserve Bank of San Francisco Economic Review, No. 3, pp. 3-16.

Kydland, Finn E. and Prescott, Edward C., (1982), "Time to Build and Aggregate Fluctuations", Econometrica, Vol. 50, No. 6, pp. 1345-1370.

Lindé, Jesper, (1999), "Testing for the Lucas Critique: A Quantitative Investigation", Revised version of Working Paper Series in Economics and Finance No. 311, Stockholm School of Economics (download at www.stanford.edu/ johntayl/PolRulLink.html).

Lucas, Robert E. Jr., (1975), "An Equilibrium Model of the Business Cycle", Journal of Political Economy, Vol. 83, No. 6, pp. 1113-1144.

Lucas, Robert E. Jr, (1976), "Econometric Policy Evaluation: A Critique", CarnegieRochester Conference Series on Public Policy, Vol. 1, pp. 19-46. 
Lucas, Robert E. Jr, (1977), "Understanding Business Cycles", Carnegie-Rochester Conference Series on Public Policy, Vol. 5, pp. 7-29.

McCallum, Bennett T., (1984), "Monetarist Rules in the Light of Recent Experience", American Economic Review, Vol. 74, No. 2, pp. 388-391.

McCallum, Bennett T., (1988), "Robustness Properties of a Rule for Monetary Policy", Carnegie-Rochester Conference Series on Public Policy, Vol. 29, pp. 173-204.

McCallum, Bennett T., and Nelson, Edward, (1999), "Nominal Income Targeting in an Open-Economy Optimizing Model", Journal of Monetary Economics, Vol. 43, No. 3 , pp. 553-578.

Rudebusch, Glenn D. and Svensson, Lars E.O., (1998), "Policy Rules for Inflation Targeting", IIES seminar paper No. 637, Institute for International Economic Studies, Stockholm University, forthcoming in John B. Taylor (ed.), Monetary Policy Rules, University of Chicago Press.

Svensson, Lars E.O., (1997), "Inflation Forecast Targeting: Implementing and Monitoring Inflation Targets", European Economic Review, Vol. 41, No. 6, pp. 1111-1146.

Taylor, John B., (1993), "Discretion Versus Policy Rules in Practice", Carnegie-Rochester Conference Series on Public Policy, Vol. 39, pp. 195-214.

Taylor, John B., (1999), "The Robustness and Efficiency of Monetary Policy Rules as Guidelines for Interest Rate Setting by The European Central Bank", Journal of Monetary Economics, Vol. 43, No. 3, pp. 655-679. 